\title{
COMPUTER ASSISTED SELF AND PEER ASSESSMENT: APPLICATIONS, CHALLENGES AND OPPORTUNITIES
}

This is the accepted pre-proof version. The final version is due to be published in the Journal of Hospitality, Leisure, Sport and Tourism Education, 2010, Vol. 9 No.1. Please consult the final version before citing.

Biosketch

\author{
Peter Lugosi, PhD \\ School of Services Management \\ Bournemouth University \\ Fern Barrow \\ BH12 5BB \\ plugosi@bournemouth.ac.uk \\ 01202961888
}

Peter Lugosi, PhD lectures in hospitality management at the School of Services Management, Bournemouth University. His previous work has considered the interaction of social and commercial forms of hospitality in contemporary society, research ethics and the relationship between hospitality and regeneration.

The data which this paper is based on was gathered through a project funded by the Higher Education Academy Network for Hospitality, Leisure, Sport and Tourism Pedagogic Research and Development Fund 2007/08 (Round 9).

\section{ABSTRACT}

This paper discusses self and peer assessment (SPA) using CASPAR (Computer Assisted Self and Peer Assessment Ratings) - a software tool designed to aid the administration of SPA. CASPAR was piloted on eight units from six subject areas (Hospitality, Leisure, Sport, Tourism, Retail and Events). Data were gathered through questionnaires from 146 students. The paper compares the SPA process and the application of CASPAR in a hospitality operations management unit with other units to identify good practice.

Keywords: self assessment, peer assessment, computer aided assessment, group work, transferable employability skills 


\section{INTRODUCTION}

Group work remains a fundamental part of teaching in hospitality, leisure, sport, tourism and events and it continues to present opportunities and challenges for students and teaching staff (Hassanien, 2006). It has been argued that working in groups encourages participants to manage individual and group goals, negotiate differences, deal with conflict and communicate effectively, which may support the development of key transferable employability skills (Boud, Cohen \& Sampson, 1999; Macpherson, 1999). However, it is often accompanied by tensions arising from interpersonal conflicts, disproportionate levels of participation and perceived unfairness of marks (Conway, Kember, Sivan \& Wu, 1993; Sivan, Yan \& Kember, 1995; Zhang, Johnston \& Kilic, 2008). One way to try to manage these issues and learn from the processes of group work is through self and peer assessment (SPA) (Johnston \& Miles, 2004; Knowd \& Daruwalla, 2003; Zhang et al., 2008). SPA is a recognised pedagogic strategy that makes it easier to identify individual contributions to group work and helps students to gain a better understanding of both its processes and outcomes (Hughes \& Large, 1993; Somervell, 1993; Williams, 1992).

A key set of challenges for lecturers in managing the SPA process is the fair allocation of marks and the administration of results and qualitative feedback for students. Numerous studies have offered practical advice on best practice in managing group work and peer and self-assessment (cf. Conway et al., 1993; Goldfinch, 1994; Knowd \& Daruwalla, 2003; Orsmond, Merry \& Reiling, 2002; Sivan, 2000). Drawing on a Higher Education Academy - Hospitality, Leisure, Sport and Tourism Network funded project, this paper builds on and adds to this body of knowledge by examining the processes of SPA using CASPAR (Computer Assisted Self and Peer Assessment Ratings) - a software tool designed to aid the administration of SPA. The aim of the paper is to offer discussion and guidance on the effective use of SPA and CASPAR within learning, teaching and assessment. In attempting to meet this aim, the paper contributes to our understanding of how SPA can be improved, regardless of whether it is conducted using CASPAR or a paper-based system. It also builds on existing literature on how electronic resources can enhance learning, teaching and assessment strategies (cf. Batey, 2002; Biscomb, Devonport \& Lane, 2008; Dale \& Lane, 2004; Haven \& Botterill, 2003; Lominé, 2002; McGugan, 2002). However, CASPAR's qualitative and quantitative assessment functions, and its ability to accommodate multiple assessment points, make it useful to consider SPA using CASPAR as a pedagogic strategy that combines the value added by SPA and electronic learning resources.

\section{WHAT IS CASPAR?}

CASPAR is an internet based software tool developed to manage the assessment of group work more effectively. It was developed within and funded by the Centre for Excellence in Media Practice (CEMP) at Bournemouth University (CEMP, 2008). CASPAR allows lecturers to set up group projects and students to participate in online SPA throughout the life of the project. SPA can take place once or on multiple occasions and alternative marking criteria can be set up for different assessment points to coincide with specific phases of group projects. It also allows students to provide qualitative feedback and numerical marks. CASPAR also has a project journal and live messaging service that help to facilitate the group work process. Finally, lecturers can monitor progress, moderate marks and collect feedback (see Lugosi, 2009 for further discussion 
on the system's functions and limitations).

\section{THE STUDY}

The study took place in the School of Services Management, Bournemouth University. Lecturers and students from six subject areas (Hospitality, Leisure, Sport, Tourism, Retail and Events) participated in the study. CASPAR was used on eight units (four second year undergraduate, three final year undergraduate and one masters), which had in total 288 enrolled students.

The primary method of data collection was questionnaires, distributed on paper and electronically via the Bristol Online Survey system. Students were given a questionnaire that focused on four areas: 1) personal information, including age, sex, nationality, course, level and unit on which CASPAR was used, 2) the use and functionality of the system, 3) the norms of assessment, including the establishment of the marking criteria and 4) students' appraisal of the SPA/feedback process. From the total target population $(n=288)$ a $50.69 \%$ response rate was obtained $(n=146)$.

Problem formulation and analysis

Initial feedback from tutors about their teaching and assessment highlighted that the establishment of the marking criteria and the SPA was conducted differently on the second year Production and Service Operations Management (Ops Man) unit than on the other units. Within the Ops Man unit the marking criteria was established collaboratively with students and the SPA process was taught alongside concepts of empowerment (cf. Lashley, 2001). Moreover, it was stressed to students during the briefing that SPA should be viewed as a developmental exercise as much as punishment or reward for contribution. They were instructed to provide written feedback that identified one area in which their peers were good and one area where they needed to improve. The explicit instruction to be critical and positive in their feedback sought to encourage reflective learning and peer-led self development. Colleagues on other units also stressed the developmental aspect of SPA but consultation on the marking criteria and SPA introduced as part of the teaching of empowerment were not part of the learning and teaching strategies for the other units from which student responses were gathered. Students from one unit were given the opportunity to participate in the development of their assessment criteria, but none of those students participated in the survey.

Nevertheless, it was assumed that the different approach to SPA was an influencing factor that shaped students' perceptions of both the SPA process and its outcomes.

Following the production of descriptive statistics, the sample was split into two groups: one group, which used CASPAR on the Ops Man unit ( $n=65)$, and a second group, which included students from all the other units $(n=81)$. The Mann-Whitney test was used to measure differences between the two groups, and where statistically significant differences were observed $(p<.05)$, the nature of the differences was examined and effect size ( $r$ ) calculated (see Field, 2005). Following Cohen (1992), Field (2005, p.32) argued that the effect size is a "standardised measure of magnitude of the observed effect"; $r=.10$ suggests low effect; $r=.30$, medium effect and $r=.50$, large effect. Highlighting statistical significance alongside effect size in this case helps to provide a more objective evaluation of the impact of the different teaching strategies on students' perceptions of the SPA process.

Limitations

The use of CASPAR was determined by the assessment schedule and the use of peer assessment and group work in the Spring and Summer term of the 2007-8 academic year. The group assessed work on many units in the School was already 
completed and it was therefore not possible to trial CASPAR. Nevertheless, CASPAR was used on a range of units from six different subject areas.

A further challenge in the data gathering was the response rate, which was just over $50 \%$. If the exercise was repeated, more pressure would be placed on students to complete the questionnaires. In future it may also be useful to design a questionnaire into the system's functions, which users have to fill in to complete the assessment.

\section{RESULTS AND DISCUSSION}

\section{Assessment procedures}

As noted previously, with the exception of the Ops Man unit, students did not participate in the setting up of the marking criteria. However, 39.7\% $(n=54)$ of respondents said that in the future they would like to participate actively in setting the marking criteria, $44.9 \%(n=61)$ remained neutral, while only $13.9 \%(n=19)$ of respondents said they would not like to be involved. There was no significant difference between the Ops Man and other students in their response $(p=.206)$. The majority of respondents $(62.9 \%, n=90)$ felt the marking criteria were explained adequately and most respondents $(69.4 \%, n=100)$ agreed with the marking criteria. $8.3 \%(n=12)$ of respondents disagreed with the marking criteria and $16.1 \%(n=23)$ felt the criteria were not explained in enough detail prior to assessment.

It is interesting to note that students on the Ops Man unit differed slightly from those on other units in their agreement with the marking criteria $(U=1946.50, p$ (2-tailed) $=.004, Z=-2.86, n=144, r=-.24)$ and in their attitudes towards explanations of the criteria $(U=1820.50, p$ (2-tailed) $=.002, Z=-3.11, n=143, r=-.26)$. Ops Man students had a greater tendency to agree with the marking criteria and to be more positive about the explanations of the criteria, although it is important to highlight that the effect size is moderate to low (Field, 2005).

This does, however, highlight the potential for using the process of setting up CASPAR, and peer assessment in general, in the development of key transferable employability skills highlighted by Yorke (2004). In the Ops Man unit, CASPAR had been piloted over two years rather than one. The unit has a practical and a theoretical element. Students studying this unit have to design operational plans for a commercial training restaurant, which includes menu planning, production planning, marketing, food production, service and data analysis, which is used to drive further improvement. In both years, students were asked to design their own assessment criteria for the development of the operational plan. The involvement of students in the design of the assessment had three purposes: firstly, as noted previously, this consultation exercise was conducted during the teaching of empowerment and thus illustrated to students the practicalities of different empowerment strategies (cf. Lashley, 2001). Secondly, it gave students the opportunity to engage in the entire assessment process. They could consequently develop a more nuanced understanding of the exact criteria used to assess their performance.

Thirdly, it can help students to think critically about what are assessable activities or traits and how those measures of assessment can be articulated and operationalised. Initial suggestions from students on the Ops Man unit often included very general categories of assessment, for example, "attitude", "performance", "contribution." Through discussions in lectures and seminars these were refined and in some cases abandoned and replaced by more specific criteria. These included: 1 . Contribution to group 
discussions (i.e. the amount, not the quality); 2. Reliability in carrying out allocated tasks; 3. Quality of written work/work produced; 4. Acceptance of advice and criticism, including follow-up actions; 5. Punctuality; 6. Reliability in attendance; 7. Organisation and preparation for meetings (this includes knowledge of relevant operations management principles).

Involving students in the SPA process in this way can encourage the development of meta-cognition (i.e. learning how to learn), the development of essential employability skills needed for industry (Dochy, Segers \& Sluijsmans, 1999; Macphearson, 1999), and consequently the emergence of reflective practitioners capable of critically evaluating the social and organisational worlds they inhabit (see Lashley, 1999; Tribe, 2002).

Therefore, it also responds to recent calls for students to develop a broad set of employability skills (People 1st, 2005; Yorke, 2004) and for embedding employability in the curriculum (Yorke \& Knight, 2006).

\section{Peer and self-assessment}

The peer assessment in the different units was conducted anonymously and $86.1 \%$ $(n=123)$ of respondents felt peer feedback and marking should be anonymous. Just over half $(53.9 \%, n=77)$ claimed they did not hold back from writing/marking truthfully in assessing their peers because they were worried about receiving negative marks or feedback. Approximately the same number $(51.1 \%, n=73)$ claimed they did not hold back from truthful peer assessment because of concerns that these would upset their colleagues. The results suggest that Ops Man students were more truthful and less inhibited than their colleagues in other units in their peer assessment. The fear of lower marks $(U=1716.00, p$ (2-tailed) $=.001, Z=-3.46, n=143, r=-.29)$ or the fear of upsetting colleagues $(U=2002.00, p(2$-tailed $)=.023, Z=-2.27, n=143, r=-.19)$ had less influence on their marking and feedback; but, again, the effect size is moderate to low. $60.3 \%(n=85)$ of all respondents agreed with the feedback they received from their colleagues, although only $45.3 \%(n=63)$ acted on the feedback.

Over half of those surveyed $(65.5 \%, n=93)$ agreed with the statement that they 'found the process of writing qualitative feedback helpful in learning what makes good group work.' Only 6.3\% $(n=9)$ disagreed and $5.6 \%(n=8)$ disagreed strongly with this statement, while $21.8 \%(n=31)$ claimed they neither agreed nor disagreed. Interestingly, there was no statistically significant difference in the responses of the two groups. This highlights the usefulness of using CASPAR to enhance SPA: it allows users to write qualitative feedback, at multiple points during the project, anonymously if necessary, which helps the provider and reader to reflect on the group work process. The results also bring into focus the usefulness of stressing to students that they should provide feedback for all their colleagues, and that they should be encouraged to highlight positive aspects alongside areas where they can improve. Student responses also reemphasise the usefulness of engaging in SPA within a broader process of reflective learning and development. As Moon (1999, 2004a) has argued, reflection provides important opportunities for growth and specifically the development of key employability skills (Moon, 2004b). Emphasising to students the role of SPA in the development of these skills may also help those unsure or unaware of their learning to appreciate the usefulness of such exercises. Furthermore, although many students claimed they were truthful in their assessment, it is apparent that peer assessment may still be perceived by many to be divisive. Addressing these concerns during briefing sessions with students 
can reemphasise the need to be mature and sensitive in providing collegiate feedback. Moreover, it is useful to stress that feedback should be seen as an opportunity (for future self development) rather than a threat (to current status).

The use of CASPAR and SPA within a broader process of reflective learning and skills development was reemphasised by students' responses about whether the use of CASPAR had improved their ability to work in a group. $27.2 \%(n=38)$ felt that using CASPAR improved their ability, but for a further $37.9 \%(n=53)$ it was not clear whether it helped or not. $26.4 \%(n=37)$ disagreed with the notion that it helped, while $8.6 \%(n=12)$ disagreed strongly. Ops Man students demonstrated a greater tendency to agree that it had improved their ability, although the effect size was once again moderate to low and it is therefore important to remain cautious in drawing conclusions $(U=1800.50, p(2$ tailed) $=.007, Z=-2.71, n=140, r=-0.23)$. One question raised by this result is whether students actually did not benefit from using CASPAR, or SPA, or whether they were unaware of their development. If students are simply unaware then making the potential learning outcomes for this exercise more overt is a key challenge for lecturers. If it does not help them to develop employability skills, then lecturers have to question whether it is simply used as a panoptical technique of surveillance and control (Foucault, 1991) through which students can assert power over colleagues. As Tan (2004) argued, self assessment, and by extension peer assessment, can disempower students and discipline them into compliance. CASPAR and SPA in general may therefore be deployed purely instrumentally to maintain a social order. Alternatively, they may simply be used as pedagogic tools that provide further insights into the contribution of particular students to group work.

Whether they are used as a pedagogic tool for fairer allocation of marks, a vehicle for reflective learning or a form of surveillance, the majority of respondents $(69.4 \%, n=93)$ felt that peer assessment should take place at multiple points throughout the group project, with $30.6 \%(n=41)$ claiming that peer assessment should take place at the end. Providing students with several assessment points, using CASPAR, helps to generate formative feedback throughout the life of the group work project. Moreover, students also have opportunities to address emerging issues as well as to improve their results.

\section{CONCLUSION}

This paper emerged from an evaluation of an electronic tool, CASPAR, although many of the points raised here about the processes of its use in the Ops Man unit are applicable to SPA generally. However, it is useful to think about SPA through CASPAR as a particular pedagogic strategy that presents its own set of opportunities. CASPAR allows for multiple points of assessment and the use of different criteria at those assessment points; students receive instant feedback through qualitative and quantitative indicators, and they can also use various functions of the software, i.e. the project journal and the instant messaging, to facilitate more effective group work. Collecting, collating and distributing marks and feedback through a manual method, for example a paperbased approach, would require much greater levels of lecturer input.

The effectiveness of SPA and CASPAR, like that of any other pedagogic tool, is determined by how it is used within learning, teaching and assessment strategies. It is interesting to note that the students studying on the Ops Man unit, and who consequently used SPA/CASPAR as part of a broader reflective learning approach, had a greater tendency to agree that the marking criteria was clearly explained and they tended to feel 
more positive about the criteria used in their assessment. Ops man students were also less likely to be inhibited in their peer marking and feedback. They also showed a greater tendency to react positively toward the statement that their ability to work in a group had improved through SPA using CASPAR. It is useful to stress that the effect sizes of the different group responses were medium to low, and therefore it is important to remain cautious in drawing conclusions. Nevertheless, if they are valid, they highlight the value of SPA through CASPAR within a multifaceted pedagogic strategy.

SPA using CASPAR can provide insights into individual performance and group dynamics. It can also shed light on individuals' perceptions of their own capabilities, as well as the perceptions of their peers. For students they can provide a fairer and more transparent method for allocating marks for different group members. However, SPA and CASPAR can also be used within a more ambitious development process. As well as giving students a sense of empowerment, it can also be used to demonstrate the opportunities and challenges offered by different empowerment strategies. A critical awareness of this is undoubtedly an important quality for graduates. Moreover, both the processes and the outcomes of SPA using CASPAR (i.e. marks and qualitative feedback) can be used within a broader strategy of reflective learning through which students can develop key employability skills.

\section{REFERENCES}

Batey, J. (2002). Web page implementation and cultural change within a first year undergraduate module. Journal of Hospitality, Leisure, Sport and Tourism Education, 1(1), 51-60. DOI:10.3794/johlste.11.15

Biscomb, K., Devonport, T. J., \& Lane, A. M. (2008). Evaluating the use of computer aided assessment in higher education. Journal of Hospitality, Leisure, Sport and Tourism Education, 7(1), 82-88. DOI:10.3794/johlste.71.181

Boud, D., Cohen, R., \& Sampson, J. (1999). Peer learning and assessment. Assessment and Evaluation in Higher Education, 24(4), 413-426. DOI: 10.1080/0260293990240405

CEMP (2008). Centre for Excellence in Media Practice, About CASPAR Retrieved January 11, 2009, from http://www.cemp.ac.uk/caspar/origins.html

Cohen, J. (1992). A power primer. Psychological Bulletin, 112(1), 115-159. DOI: $10.1037 / 0033-2909.112 .1 .155$

Conway, R., Kember, D., Sivan A., \& Wu, M. (1993). Peer assessment of an individual's contribution to a group project. Assessment and Evaluation in Higher Education, 18(1), 45-56. DOI: 10.1080/0260293930180104

Dale, C., \& Lane, A.M. (2004). 'Carry on talking': Developing ways to enhance students' use of online discussion forums. Journal of Hospitality, Leisure, Sport and Tourism Education, 3(1), 53-60. DOI:10.3794/johlste.31.62

Dochy, F., Segers, M., \& Sluijsmans, D. (1999). The use of self-, peer and co-assessment in higher education: A review. Studies in Higher Education, 24(3), 331-350. DOI: $10.1080 / 03075079912331379935$

Field, A. (2005). Discovering statistics using SPSS (2nd ed.). London: Sage.

Foucault, M. (1991). Discipline and punish: The birth of the modern prison. London: Penguin.

Goldfinch, J. (1994). Further developments in peer assessment of group projects. 
Assessment and Evaluation in Higher Education, 19(1), 29-35.

DOI: 10.1080/0260293940190103

Haven, C., \& Botterill, D. (2003). Virtual learning environments in hospitality, leisure, tourism and sport: A review. Journal of Hospitality, Leisure, Sport and Tourism Education, 2(1), 75-92. DOI:10.3794/johlste.21.36

Hassanien, A. (2006). Student experience of group work and group assessment in Higher Education. Journal of Teaching in Travel and Tourism, 6(1), 17-39. DOI: 10.1300/J172v06n01_02

Hughes, I. E., \& Large, B. J. (1993). Staff and peer-group assessment of oral communication skills. Studies in Higher Education, 18(3), 379-385. DOI : $10.1080 / 03075079312331382281$

Johnston, L., \& Miles, L. (2004). Assessing contributions to group assignments. Assessment and Evaluation in Higher Education, 29(6), 751-768. DOI : $10.1080 / 0260293042000227272$

Knowd, I., \& Daruwalla, P. (2003). Peer assessment in hospitality education. Journal of Teaching in Travel and Tourism, 3(1), 65-85. DOI: 10.1300/J172v03n01_05

Lashley, C. (1999). On making silk purses: Developing reflective practitioners in hospitality management education. International Journal of Contemporary Hospitality Management, 11(4), 180-185. DOI: 10.1108/09596119910263586

Lashley, C. (2001). Empowerment: HR strategies for service excellence. Oxford: Butterworth-Heinemann.

Lominé, L. K. (2002). Online learning and teaching in hospitality, leisure, sport and tourism: Myths, opportunities and challenges. Journal of Hospitality, Leisure, Sport and Tourism Education, 1(1), 29-42. DOI:10.3794/johlste.11.13

Lugosi, P. (2009). CASPAR: A web-based tool for self and peer assessment in group work. LINK, 24. (In-press)

Macpherson, K. (1999). The development of critical thinking skills in undergraduate supervisory management units: Efficacy of student peer assessment. Assessment and Evaluation in Higher Education, 24(3), 273-284. DOI: $10.1080 / 0260293990240302$

McGugan, S. (2002). Asynchronous computer mediated conferencing to support learning and teaching: An action research approach. Journal of Hospitality, Leisure, Sport and Tourism Education, 1(1), 29-42. DOI: $10.3794 /$ johlste.11.9

Moon, J. A. (1999). Reflection in learning and professional development: Theory and practice. London: Kogan Page.

Moon, J. A. (2004a). A handbook of reflective and experiential learning: Theory and practice. London: RoutledgeFalmer.

Moon, J. A. (2004b). Reflection and employability. York: The Higher Education Academy.

Orsmond, P., Merry, S., \& Reiling, K. (2002). The use of exemplars and formative feedback when using student derived marking criteria in peer and self-assessment. Assessment and Evaluation in Higher Education, 27(4), 309-323. DOl: $10.1080 / 0260293022000001337$ 
People 1st (2005). Hospitality, leisure, travel and tourism: A skills and labour market profile. London: People $1^{\text {st }}$.

Sivan, A. (2000). The implementation of peer assessment: An action research approach. Assessment in Education, 7(2), 193213. DOI: $10.1080 / 713613328$

Sivan, A., Yan, L., \& Kember, D. (1995). Peer assessment in hospitality and tourism. Hospitality and Tourism Educator, 7(4), 4-20.

Somervell, H. (1993). Issues in assessment, enterprise and higher education: The case for self-, peer and collaborative assessment. Assessment and Evaluation in Higher Education, 18(3), 221-233. DOI: 10.1080/0260293930180306

Tan, K. H. K. (2004). Does student self-assessment empower or discipline students? Assessment and Evaluation in Higher Education, 29(6), 651-662. DOI: 10.1080/0260293042000227209

Tribe, J. (2002). The philosophic practitioner. Annals of Tourism Research, 29(2), 338357. DOI: 10.1016/S0160-7383(01)00038-X

Williams, E. (1992). Student attitudes towards approaches to learning and assessment. Assessment and Evaluation in Higher Education, 17(1), 45-58. DOI : $10.1080 / 0260293920170105$

Yorke, M. (2004). Employability in higher education: What it is - what it is not. York: The Higher Education Academy.

Yorke, M., \& Knight, P.T. (2006). Embedding employability in the curriculum. York: The Higher Education Academy.

Zhang, B., Johnston, L., \& Kilic, G. B. (2008). Assessing the reliability of self- and peer rating in student group work. Assessment and Evaluation in Higher Education, 33(3), 329-340. DOI : $10.1080 / 02602930701293181$ 